\title{
Taxation in Law and Economics: A Brief Review for Public Policy Decisions
}

\author{
Hung Nguyen, Ph.D. \\ Fort Hays State University \\ 600 Park St, Hays, KS 67601, United States \\ \& \\ Shenyang Normal University \\ 253 Huanghe N St, Huanggu District, Shenyang, Liaoning, China
}

\begin{abstract}
The purpose of this research paper is twofold. The first chapter gives a survey of the experimental literature on the perception of individuals with respect to their own tax burden and its effect on economic decisions. Within this chapter, several strands of literature are discussed, namely: perception of marginal tax rates, influence of tax complexity on tax perception, taxation and incentives to work, tax salience, and tax morale and fairness. The second chapter considers whether knowledge of the tax law is socially desirable. Here, whether knowledge of the tax law is desirable depends on three factors: expectations about the tax in the absence of knowledge, the type of tax, and the quality of the tax. Then, apply this to various policy decisions where knowledge of the tax law is a key variable, including the regulation of tax advisors, hidden taxes, and whether individuals have the socially optimal incentive to seek knowledge of the tax law.
\end{abstract}

\section{Chapter 1:An Overview of Tax Perception}

\section{Introduction}

Economic literature traditionally starts from the assumption that tax payers perceive their effective tax burden correctly. Obviously, if this assumption is not correct, a number of standard results would have to be questioned. A number of publications have taught us that tax burden an individual perceives may differ from his or her effective tax burden. This chapter gives a survey of the experimental literature on this topic. By the term "perceived tax burden" we understand the tax burden which a person explicitly estimates when he or she is asked to as well as an estimate which a person implicitly makes when taking an economic decision, that is, on labor supply or asset allocation, or when voting in elections.

This chapter is organized as follows: Sections 1 to 5 each cover one specific aspect of tax perception. Section 1 reports on papers which examine whether tax payers correctly estimate their marginal tax rate; in Section 2 the influence of tax complexity on this estimate is treated. Section 3 embraces studies analyzing the relation of tax perception and labor supply. Empirical tests of the hypothesis of liability side equivalence are presented in Section 4. Section 5 gives an overview of literature on tax morale and fairness.

\section{Section 1: Perception of Marginal Tax Rates}

There are numerous studies, archival and surveys, which analyze the perception of individual marginal tax rates in a progressive income tax. The findings are not consistent but a majority of authors reveal misperceptions. It is not yet examined adequately which factors influence this misperception. For example, Konig et al. (1995) find school education as the main determinant, Fujii and Hawley (1988) show that even physicians have difficulties to state the correct marginal tax rate. This suggests not only the level but also the kind of education, especially the existence of economical knowledge, is important. Nevertheless, it seems that more tax experience improves individual's perception. For example, Lewis (1978) shows that older individuals and Rupert and Fischer (1995) state that individuals with higher income are more accurate in their estimates. Moreover, Gensemer et al. (1965) and Rupert and Fischer (1995) claim that a higher financial knowledge has a positive influence on tax rate perception. In addition, as early as in the sixties, Enrick (1964) revealed that the tax burden is not perceived correctly. In two surveys he asked for the individual tax burden and found that the interviewees systematically undervalue their real tax burden. Subsequently, other researchers analyze survey data to obtain more knowledge regarding the perception of marginal tax rates.

All of these studies reveal that taxpayers' perception of marginal tax rates is not correct but the direction of the misperception observed is not the same in all papers. One reason could be that the misperception differs between countries, that is, due to different tax complexities. However, there are also inconsistent findings for the United States alone. To measure a misperception, taxpayers estimate their actual marginal tax rate have to be compared. For a correct determination of the true marginal tax rate, taxpayers' taxable income has to be known exactly. Since researchers have no access to personal income tax data, they could only estimate or generalize this amount. 
For example, Fujii and Hawley (1988) and Rupert and Fischer (1995) assume that each household took standard deductions. As individuals may have declared higher actual deductions instead, this assumption obviously leads to a bias and distorts the comparison of estimated and true marginal tax rate. Another potential reason for inconsistency could be the additional amount of income which is assumed in the studies.

Besides there are some econometric studies which analyze individuals' perception of marginal tax rates. Most of these studies are based on a model first developed by Rosen (1976a / 1976b) and use multivariate methods, including OLS, NLLS or ML-estimation. In these analyses, the dependent variable is the number of work hours over a specific time period of an individual. The research question is: Do individuals base their work hours' decisions on a correctly perceived marginal tax rate? Therefore, independent variables, which possibly have influence on the dependent variable, are the individual marginal tax rate, the gross wage and some other personal characteristics such as number of children and degree of education. The resulting estimators for the coefficients of these independent variables are used to compute a parameter of misperception.

Peek and Wilcox (1984) use a similar technique to examine the influence of tax rate changes on rates of return. The main finding is that after a tax rate change, pretax rates or return vary in such a way that the same net rates are achieved as before. This gives evidence that tax rates are perceived correctly in investment allocation.

Consequently, there are a number of reasons which possibly explain the inconsistent results between the econometrics studies. First, the more complex or non-transparent a tax regime the more pronounced might be the misperception. Thus, one reason for the disparity between these studies could be a difference in tax complexity or transparency of tax law among the countries analyzed. Second, tax reforms may have led to an increase of tax complexity. Therefore, misperception may rise over time. Third, the econometric model which is used to compute the parameter of misperception is varied between the studies. For example, different individual characteristics are used as independent variables and different statistical methods are applied. Fourth, there may be a gender effect or, fifth, sample size may be too small in some cases. These potential reasons for inconsistency should be considered in further research. Moreover, a comparative study is desirable which analyzes all econometric studies with respect to these problems.

In addition to this strand of literature, in a few studies the perception of special tax provisions and the influence of the tax framing on perception are analyzed. In Fochmann et al. (2010a) the perception of income taxation with different loss education rules and their influence on investment behavior is analyzed experimentally. Subjects' task is to choose between two investment alternatives that have the same expected value, but differ in variance. In the baseline treatment no tax is levied on gains and no loss deduction appears in case of a loose. Contrary to this, in the perception treatments gains are subject to a proportional income tax with a rate of 35\% but loss offset rules differ between these treatments. Independent of the special tax provisions, after-tax payoffs of the investment alternatives in all perception treatments are equal to the payoffs in the baseline treatment. Hence, it is to be expected that subject take the same decisions in all treatments. The authors find that the number of risk seeking investors is not significantly greater than the number of risk averse investors when there is no taxation. The same is true in the case of proportional income taxation without loss deduction. However, when there is a partial or capped loss deduction rule, a strong and significant bias towards risk seeking behavior is observed. It seems that the value of loss deduction is overestimated. Since losses are optimistically assumed to weigh less in these situations, the decision makers feel safe to take on greater risks.

\section{Section 2: The Complexity of Taxation}

The complexity of a decision problem can be characterized by the variety of influencing factors and by the extent of their dependences. As mentioned earlier, tax complexity may be responsible for the misperception of tax rates. Congdon et al. (2009: 378) claim that "individuals will respond not to the tax rate as it is set but as they construe it."Conceivably, the more complex a tax system is the larger may be this difference between the legal tax and the construed tax. As a result, this bias can affect real decision problems. Chetty and Saez (2009) find in a field experiment that extra information about the Earned Income Tax Credit (EITC) affects labor supply and earnings decisions of the recipients. It seems that the EITC system is too complicated to be perceived correctly. However, additional information reduces complexity and recipients adjust their behavior.

A number of experimental analyses also show that the correct perception of tax effects in individuals' decision making is influenced by the complexity of the tax system. However, these papers do not investigate complexity in the sense defined above, but rather vary the complexity and transparency of the presentation of tax scales. In these experiments, the outcome from a certain action is subject to tax. Between the treatments, the complexity or presentation of tax base and tax scale is varied. The main finding of these papers is that the higher tax complexity is the worse is the subjects' judgment and quality of decisions. Furthermore, it can be observed that even market efficiency is influenced by tax complexity. Compared to a control treatment, subjects need more rounds until the market equilibrium is reached. Boylan and Frischmann (2006) show the impact of complexity by means of a laboratory experiment. The experiment consists of two treatments which differ only in tax complexity. 
In each treatment, subjects attain gains by trading goods. In the low complexity treatment, these gains are subject to a linear tax at a rate of $40 \%$ independent of the respective gain level. In the high complexity treatment, the tax payment is determined by different elements: first, gains are subject to a tax at a rate of $15 \%$ independent of the gain level plus, second, a negative or positive tax payment which depends on the pretax gain.

The respective amounts are displayed in tables to the participants and are chosen in such a way that effective tax rate in the high complex treatment is also $40 \%$ independent of the pretax gain level. Thus, both treatments are identical with regard to the tax burden but in the high complexity treatment the total tax payment has to be derived from instructions. The results of this experiment confirm the authors' hypothesis that tax complexity has a negative impact on investor profits. In the high complexity treatment, prices are quantities are above the market equilibrium thus causing market inefficiencies. However, it can be observed that differences between both treatments diminish over the course of the experiment. Possibly, this can be attributed to learning effects in the high complexity treatment. But, the analysis of a control question regarding the effective tax rate which was asked at the end of the experiment reveals that no subject realized the correct tax rate. Only three out of twelve answers were in the right interval between $30 \%$ and $45 \%$.

In an experiment by Bartolome (1995), complexity is generated by a variation in the presentation of the tax scale. The first form of presentation is a tax table in which the absolute tax burden is specified for a given taxable income but no explicit tax rate is given. In the second form the tax scale is described verbally and the marginal tax rates are stressed out explicitly. Thus, both descriptions represent the same progressive tax scale but the marginal tax rate cannot be identified immediately with the first form. The results of this experiment reveal that subjects consider taxation in their investment decisions independent of the tax scale presentation. However, the majority of participants use the average and not the marginal tax rate for their decisions in the treatment with the tax table. Most subjects use the average tax rate as if it is the marginal tax rate. Therefore, they consider the tax burden in principle but undervalue the real tax effect. Contrary to these results, subjects in the second treatment use the marginal tax rate in most cases. The author concludes that the correct use of marginal tax rates can be obtained by a transparent specification of marginal tax rates whereas tax tables tend to mislead taxpayers. Likewise, Rupert and Wright (1998) use four different presentation forms of a tax scale which differ in the visibility of marginal tax rates. These authors also show that a higher visibility of marginal tax rates leads to better investment decisions.

With an experiment, Rupert et al. (2003) analyze to what extent a more complex tax system influences the perception of marginal tax rates and the decision making process of an individual. Complexity is measured by the limitation of possible tax deduction in a tax system. Therefore, the more limitations exist the more complex is the tax system. The limitations are chosen in such a way that the effective marginal tax rate is the same for all treatments independent of the complexity of the respective tax regime. The authors show that subjects in the more complex tax systems are not able to estimate their effective marginal tax rates accurately. The results suggest that subjects do not adjust their estimates to account for the effects of limitations and, therefore, undervalue their true marginal tax rate. An increase of complexity leads to more misperceptions. As a result of this misconception, participants in the more complex treatments choose the optimal investment less frequently. Thus, low complexity leads to a better performance and to more efficiency.

\section{Section 3: Taxation and Incentive to Work}

Several experimental studies examine the impact of the tax rate level, the tax scale, and the kind of taxation, levied on income or on consumption, on labor supply. It can be summarized that a negative relation between the incentive to work and the marginal tax burden is observed,as suggested by Swenson (1988) and Sutter and Weck-Hannemann (2003). Furthermore, an increase in gross wage induces a higher labor supply in an indirectly progressive tax scale (Sillamaa 1999a). Another experiment reveals that labor supply is less affected when the tax is levied on consumption than when it is levied on income (Blumkin et al. 2008). Using a linear tax on wages, the Laffer curve is verified and the highest tax revenue is achieved with tax rates of 50\% and 73\%, respectively (Sutter and WeckHannemann 2003 and Swenson 1988).

Sillamaa (1999) conducts several experiments to analyze the impact of different tax regimes on labor supply. In Sillamaa (1999b), participants are divided into two groups at the beginning of the experiment. In one group, subjects' decision task is to decode numbers into letters with the use of a paper decoding sheet. The subjects in the other group have to type a single character in an input mask. The income from each work is taxed but the tax scale differs from period to period. Therefore, participants are faced with several tax regimes in every work period. The author focuses on two special tax regimes: a "regressive tax" and a tax scale with a marginal tax rate of zero at the top income ("zero-tailed regressive tax").

Both tax regimes are characterized by decreasing marginal tax rates. But contrary to the "regressive tax," no further tax is levied in the second system if a certain work output is exceeded by a participant. Until this limit, taxation is absolutely identical in both tax regimes. The limit is set to $105 \%$ of an individual's work output (number of correctly decoded or typed characters) in the period with the regressive tax. 
Thus, the zero-tailed regressive tax regime is always implemented after the regressive tax regime. However, subjects are unaware of this $105 \%$-threshold. Theoretically, the zero-tailed regressive tax regime should lead to a higher labor supply. Indeed, both working groups exhibit a significant higher work output than in the regressive tax regime. Thus, the existence of this theoretical incentive is confirmed experimentally.

In a further experiment, Sillamaa (1999a) examines the impact of an increasing gross wage on labor supply. Again, participants' decision task is to decode numbers into letters and the income from work is taxed. The author distinguishes two progressive tax scales: a directly progressive tax scale and an indirectly progressive tax scale with an exemption and a constant tax rate. The second tax scale is chosen in such a way that both taxes are equivalent with regard to the level of work effort and after-tax consumption before gross wage increase. In the following, it is hypothesized and confirmed that an increase in the gross wage induces a higher labor supply with the linear tax than with the directly progressive tax.It can be noted critically that in both experiments of Sillamaa a neutral framing is applied, that is, the author consciously avoids any reference to taxation. Participants are only informed about net wages, they are not aware of the interaction of gross wage and tax payments leading to this payoff.

In Swenson (1998) and Sillamaa (1999c) the influence of different tax rate levels on labor supply decisions is analyzed. In both labor experiments the tax rates $12 \%, 28 \%, 50 \%, 73 \%$ and $87 \%$ are applied and each participant is confronted with all of them. Contrary to Swenson, Sillamaa does not display tax rates but only net wage rates. In both experiments, the total tax revenue of one period is redistributed to the subjects. The redistribution mechanism differs. In Swenson (1998), redistribution is determined by the tax payments of several participants. From this total amount, each subject receives a share at random in the next period. In the study of Sillamaa, each participant receives a certain share which only depends on his own tax payment. The amount is determined by the personal tax payment of the previous period plus/minus a random amount of at most $5 \%$ of this tax payment. Randomization is used to veil the functional relation between tax payment and redistribution. By the use of a complete redistribution of tax revenues, both authors claim to eliminate an income effect completely. Thus, a participant's change of behavior can be attributed to the substitution effect between work and leisure. In this setting, an increasing tax rate does not lead to a decrease in income when participants supply the same amount of labor. Nevertheless, due to a substitution effect, labor supply is expected to decrease under a balanced-budget increase in the tax rate (Lindbeck 1982). Indeed, both experiments confirm this theorem. However, in the experiment of Swenson, this is not true for the lowest tax rate since labor supply decreases compared to the labor supply in the case of higher tax rates. This may be a random result or the effect of the redistribution mechanism installed which does not eliminate the income effect perfectly.

From the viewpoint of a rational decision maker, a tax on labor income and tax on consumption are complete substitutes if earned income must be spent immediately on consumption or if no interest-bearing investment is available. Thus, labor supply should be the same under both forms of taxation. Blumkin et al. (2008) examine this theoretical equivalence in a laboratory experiment and focus on the incentive to work under each tax regime. The experiment consists of three different phases. The first phase is used to measure the work ability, or productivity, of each participant. For this purpose, subjects have to solve by hand as many as possible two-digit by two-digit multiplication questions in three minutes. For every correct answer, participants get money. The second phase is applied to determine the work-leisure preference of a test person. Like in the first phase, participants are asked to solve multiplication questions. For each correct solution, a subject now receives two points which can be converted into two consumption goods: falafel or pizza vouchers. Contrary to the first phase, a participant is able to stop working within the time period and do nothing. In this case, a participant gets soft drink voucher for every 15 seconds of leisure time. Through this mechanism, subjects gain utility from leisure. Consequently, test persons do not earn points for falafel or pizza vouchers during leisure time. The third phase is identical to the second, but a tax either on labor income or on consumption is levied. In the labor income tax treatment a 50\% wage tax is imposed on the earnings. Thus, a subject receives only one point for each correct answer instead of two. In the consumption tax treatment a $100 \%$ tax on consumption is imposed on ever consumption good. Therefore, the price of each consumption good has double compared to phase two, whereas the value of a correctly answered question is still two points. The leisure good remains untaxed in either tax treatment. As such, equal labor supply lead to identical consumption abilities and tax burdens in both treatments and labor supply should be the same. A comparison of phase two and three reveals that the substitution effect is greater than the income effect in this experiment. This means that taxation leads to a decreasing labor supply and, therefore, to a higher preference for leisure. This significant result holds for both tax treatments. However, the decrease is much more pronounced in the labor income tax treatment than in the consumption tax treatment.

Thus, it can be concluded that the incentive to work is higher in case of a consumption tax. The theoretical equivalence of both tax regimes cannot be verified in this experiment. According to the authors, a potential reason for this phenomenon may be that subjects underestimate the cost of consumption in the future. The authors develop a model based on the results of this experiment to show that a shift from an income tax to a consumption tax reduces the excess burden from taxation. 


\section{Section 4: Tax Salience}

The theoretical literature is mainly based on the assumption that tax incidence is independent of the market side, supply or demand, on which a tax is levied. This theorem is known as "Liability Side Equivalence Principle" (or LSE).

In a field experiment, Chetty et al. (2009) observe that consumers do not react correctly to taxes that are not salient. In this study, it is shown that taxes which are not explicitly posted on the price tags are totally ignored when calculating the total price of the purchased goods. If both the pretax price and the tax-inclusive price are posted, consumers perceive the total tax-inclusive price correctly. In a number of laboratory experiments, tax salience and its influence on economic decisions is examined. In all of these studies, non-salient taxes are reflected by taxes which are levied on the other market side. Conclusions from these results are mixed. In most experiments, it appears that subjects realize the incidence of an indirect - non-salient - tax. Further, in some studies correct perception by the participants occurs not immediately. Depending on the experimental design, subjects need some rounds until learning effects lead to an efficient pricing.

A laboratory experiment of Sausgruber and Tyran (2005) shows that learning effects are necessary for a correct tax perception. In this experiment, participants have to trade goods on a market but take only the role of the demand side. The supply side is automated which is known to the subjects. The experiment consists of four phases and each consists or 15 trading periods. After the first phase without taxation, subjects have to vote on a proposal to tax market transactions and to redistribute the tax revenues to market participants (public good). If participants reject this proposal, no tax is levied and also no public good is provided like in the first phase. Depending on the treatment, participants have the option either to implement a direct or an indirect tax system. Note that participants cannot choose between both tax systems but only vote whether to implement the respective tax regime or not. The authors have designed both different tax settings in such a way that the direct tax cannot be shifted to sellers and that the indirect tax is shifted completely to buyers. This mechanism is unknown to the participants. As a result, buyers bear the full tax burden and, therefore, both treatments are completely identical in an economic sense. Since buyers and sellers participate in equal shares from the provided public good, the acceptance of the proposal in all cases leads to a decreasing net income for the participants. Therefore, voting for the introduction of a tax is irrational since the buyers' share of the tax revenue is always lower than the tax they have to bear.

In Ruffle (2005), participants are confronted with a tax implementation either on buyers' or on sellers' side after some tax-free periods. In two further treatments, the buyer or the seller side obtains a subsidy which can be considered as a negative tax. Theoretically, tax burden and subsidy relief depend only on the elasticity of demand and supply. The LSE should hold for the tax as well as for the subsidy treatments. In this experiment, participants trade goods on a pit market. Thus, unlike other studies, price negotiation is not conducted anonymously. Rather, a participant may select his trading partner by himself. In total, 552 subjects participated in this experiment. Like in the tax free periods, the theoretical price equilibrium is reached after the tax or the subsidy implementation. Moreover, the variance of the price diminishes over several periods. This indicates that all subjects match with the equilibrium and can be seen as a confirmation of the LSE. However, the variance of the price in the subsidy treatment is higher compared to the tax treatment. Possibly, this is caused by a lack of experience with subsidies compared to taxes. With regard to the number of participants within each group, the experiment reveals that in smaller groups equilibrium is reach more slowly. Altogether, it can be claimed that individuals realize very well to what extent they are burdened with a tax - irrespective of whether they themselves or the other market side have to pay it.

\section{Section 5: Tax Morale and Fairness}

In principle, tax evasion can be considered to be individually rational if the taxpayer is still able to make use of the public good since he benefits - as a free rider - from the tax payments of others. Allingham and Sandmo (1972) show theoretically that tax compliance increases if audit probability or the level of penalty rises. The influence of the tax rate on tax compliance is ambiguous. The authors show that the tax rate effect depends on taxpayer's risk attitude. In the literature, tax morale generally indicates the truthful declaration of a taxable base and has been intensively analyzed in experiments. For the most part, the theoretical findings are confirmed, especially for the statements regarding audit probability and penalty.

Similar studies regularly reveal that participants' tax morale is higher than the tax morale of the human economic. Many experiments are design in a way that rational behavior would require complete tax evasion. However, participants regularly do not behave in the way predicted. As a result, it is generally supposed that individuals have a kind of intrinsic motivation to pay taxes. Some studies examine the influence of the use of taxpayers' money on the individuals' willingness to evade taxes. For example, Kolm (1973) establishes a tax evasion model where the utility of a tax financed public good is explicitly integrated in the decision about the extent of tax evasion. Further, Vogel (1974) conducts a survey in Sweden and find that the willingness to evade taxes decreases if some benefit is provided in return for the tax payment. Moreover, Lewis (1979) attains similar results for Great Britain. 
Feld and Tyran (2002) conduct a laboratory experiment and implement three treatments where a tax is levied to finance a public good which offers some benefit for the participants. A subject's declared income serves as tax base. Contrary to other studies, the audit probability is set to $100 \%$ and, therefore, tax evasion is always uncovered. In the first treatment, a detected tax evasion remains without consequences since there is no fine on tax evasion.

Under the assumption of rational behavior, this design induces complete tax evasion. Indeed, participants declared $30 \%$ of their income on average although there is no risk of having to pay tax arrears or of being penalized. It seems that an intrinsic motivation to pay taxes is responsible for this finding. In the second treatment, tax evasion is punished with an exogenous fine which is set to $20 \%$ of the maximum declarable amount, but tax evaders are not required to pay tax arrears in this experiment. The penalty parameter is chosen in such a way that a complete tax evasion is still rational despite the penalty and the audit probability of $100 \%$. As a result, declared income rises slightly to $38 \%$ on average. However, the difference between the results of the first and second treatment is statistically not significant. Therefore, the implementation of an exogenous fine induces no change in participants' tax morale.

In the third treatment, the impact of participants' choice to implement a penalty or not on tax morale is examined. If the proposal is accepted, penalty is identical to the exogenous fine of the second treatment. However, each subject has to declare his income before knowing the voting result. The authors observe less tax evasion in this treatment with an endogenous fine compared to the treatment with the exogenous fine. They suppose that direct voter participation is responsible for the lower extent of tax evasion since the legitimacy of policy outcomes increases. This means that having influence on the implementation of the tax or fine system raises participant's tax morale. This is in line with the finding that participants who vote for the proposal reveal higher tax morale compared to the exogenous treatment. A further explanation for increasing tax compliance might be reciprocity. It seems that the own decision for the proposal is understood as a signal to other subjects for a higher individual tax morale. This signal may induce other participants to be more compliant, too. Therefore, tax morale increases if further pro-voters appear. It can be stated that "the more subjects expect the others to comply with the tax law, the higher is their tax morale was well" (Feld and Tyran 2002: 218).

Spicer and Becker (1980) and also Fortin et al. (2007) find further interesting results regarding fairness effects. With respect to participants' income declaration, they observe that individual tax evasion increases if the own tax rate rises relative to the rate of the other participants. A reason for this might be that subjects attempt to attain fiscal equity through tax evasion. Guth et al. (2005) examine how far tax morale depends on a central or decentralized tax collection. Therefore, two treatments are implemented: For one thing, a decentralized tax collection is applied, i.e., tax revenue of a region is used to provide a public good in the same region. For another thing, total tax revenues of two regions are levied centrally and are redistributed in equal shares to both regions afterwards in the other treatment. As a result, a decentralized tax collection causes a higher level of tax compliance.

In a study of Guth and Sausgruber (2008), election preferences for different tax regimes and also tax morale under these regimes are analyzed. Therefore, a tax regime with an income tax and a tax regime with an income and a distorting commodity tax are compared. In both tax regimes, income taxes can be evaded without any punishment but the commodity tax cannot be evaded. Tax revenues from both taxes serve to provide a public good. In this experiment, a complete evasion of income tax is rational from an individual's perspective. However, every subject can improve his or her position if all subjects pay income taxes and, therefore, the public good is provided to the highest possible extent. It is expected that participants vote for the tax regime with income and commodity tax because this regime promises a higher payoff if subject behave rationally and evade income taxation. Indeed, experimental results reveal the opposite. Participants prefer the tax regime with just income tax. In addition, subjects in this tax regime exhibit higher tax morale. This contradicts the results of a survey by Cullis and Lewis (1985) whereby interviewees favor a commodity tax over an income tax for an increase in tax collection. Neuroeconomics possibly offer additional insight into individuals' high tax compliance which cannot be explained in the model of the human economic. For example, Harbaugh et al. (2007) show that both compulsory levies and voluntary donations to a charity cause similar patterns of brain activity that are observed when the tested- person receives a payment in his own favor.

The authors interpret this as evidence for perfect altruism as well as for the motive of a "warm glow of giving." A further strand of literature attempts to measure subjective effects of taxation and subjective assessment of its fairness.

\section{Chapter 2: Assessments of Tax Law}

\section{Introduction}

In most cases, knowledge of the law is desirable. We want people to know how to dispose of hazardous waste, to enter into binding contracts, and to demarcate their property. People should know the extent of their free speech rights and that assault is criminal. Tax law, however, may be different, at least with respect to knowledge of the law prior to taking action. Often tax law tries to achieve its goals - raise revenue, redistribute, and so on - while 
minimizing changes to behavior, and behavioral changes may be minimized if people do not know the details of the law. For the tax law, ignorance may be bliss, if not privately, at least socially.

Understanding whether and when knowledge of the tax law is desirable is central to a number of important policies. For example, tax systems can be designed to be easier or harder for people to understand and incorporate into their behavior. In their selected works, scholars such as Liebman and Zechhauser (2004) and Schenk (2010)have suggested that it might be desirable to purposefully choose tax systems that are difficult to understand on the theory that such systems will have lower efficiency or related costs. Thus, a value-added tax (VAT) builds the tax into the price of a good so that buyers will automatically take account of the tax in their purchasing decisions. A retail sales tax, which, if taxpayers have full knowledge of the law can be made economically equivalent to a VAT, may be less transparent because it is imposed at the cash register; the prices of goods are typically displayed without the tax. The cost of determining the after-tax price under a retail sales tax is higher than with a VAT which means that taxpayers are less likely to fully understand the impact of a retail sales tax than a VAT. If knowledge of the tax law is undesirable, a retail sales tax, all else held equal, becomes relatively more desirable. Alternatively, hiding the marginal rate structure within an income tax, such as through non-transparent phase-ins and phase-outs, may be desirable (Schenk 2010).

Moreover, there has been an explosion of rules and regulations which, in turn, increasing the cost of tax advice and reducing its value. Hence, understanding whether knowledge of the tax law is socially desirable is central to evaluating these rules. If knowledge of the tax law is undesirable, we may want to limit access to tax advisors or otherwise raise the price of tax advice while these conclusions may change.

In addition, another important tax policy decision affected by this question is the extent to which the tax law can or should be uncertain. Numerous authors have advocated for uncertainty in the form of broad-based standards designed to prevent or reduce tax shelters. For example, in 2010, Congress of the United States enacted a statutory economic substance doctrine, which overlays a broad anti-abuse standard on top of the existing detailed tax rules. However, the economic substance doctrine makes it too hard for people to know what the law is (Gideon 1998). Therefore, knowledge of the tax law is socially desirable prior to individuals taking action.

\section{Section 1: Tax Policy and Key Concepts}

First, there are efficiency losses from taxation. If the goal of taxation were to raise revenue to run the government, we could simply divide the revenue needs by the number of people in the society and ask each person to pay his or her pro rata share. Because the tax would not depend on behavior, it would be efficient in that it would not distort decisions. Note that it would reduce people's income, so people might choose different things than they would without taxation. Also, most models take the size of government as fixed; these income effects are inevitable and, therefore, are not viewed as inefficient distortions.

Most of the time, tax models assume that head taxes of this sort are not possible or not desirable. Notwithstanding their simplicity, they may not be desirable because they do not differentiate among people and, therefore, do not redistribute. If we cannot use a head tax, we have to base the tax on observable attributes of the individual, such as how much he or she consumes, earns, or saves. Any choice of attributes will leave some things untaxed. For example, if we tax consumption, then non-consumption activities such as pure leisure are not taxed. More precisely, if we tax market purchases of consumption, non-market activities are untaxed. Similarly, if we tax income, leisure remains untaxed. Any tax based on observable attributes other than a head tax will leave some things untaxed.

Suppose one good is not taxed but others are. The untaxed good is usually assumed to be leisure but we do tax consumers for their earnings or their purchases. Taxation then introduces distortions as people might change their consumption behaviors, or choose to work less because taxation has changed the relative prices. The distortions come from the change in relative prices - the substitution effect. To understand the size of the distortion, we can start from a world without taxes and consider what happens when we introduce a tax on a good.

The price of the taxed good will go up, so individuals will reduce their demand for the taxed good. As a result, there will be fewer purchases of the good to tax, so tax revenue will decline. People have altered their consumption choices, which hurt them, but there is no offsetting benefit to the government in the form of tax revenue. This difference, the difference between the loss in utility to individual and the government revenue from taxes, is known as deadweight loss (DWL) - it is the loss from individuals making inefficient choices to avoid taxation.

Deadweight goes up with the square of the tax rate. To understand why, consider the change in DWL from increasing a tax by an increment (Gruber 2005). If the tax were initially zero, the DWL caused by the tax would be very small. To see why, suppose that someone consumes food until he no longer wants to spend any more on food. Say that amount spent is $\$ 1,000$. For the very last dollar spent, the benefit of the additional food is just worth the last dollar. 
The individual decides not to spend an additional dollar more because the benefit of the food is not worth the cost, and decides not to spend an additional dollar less because at that amount, the value of the food is just a tiny bit more than an additional dollar. At $\$ 1,000$ the two balance. If taxation causes that choice to be changed to only $\$ 999$ spent on food, the utility loss from not having the food but having the dollar is negligible because, at that last dollar, the benefit from spending more on food was negligible. Now if the tax was already positive and we increased it by a further increment, the utility loss would be much greater. If the tax has already distorted food purchases so that only $\$ 900$ is spent, going to $\$ 890$ imposes real costs. The DWL from additional increments of tax are greater the larger the tax. Correspondingly, if DWL from additional increments to the tax rate get bigger, the DWL itself goes up with the square of the tax rate.

Second, there are complexities in tax law. We can divide the tax literature into two central strands: the Ramsey tax literature and the optimal income tax literature. They differ in the assumptions that they make and, therefore, end up imposing somewhat different levels and types of complexity. The Ramsey tax assumes that everyone is the same so it considers a representative individual but rules out head taxes by assuming that at least one consumption good remains untaxed, which is leisure. Taxation then introduces distortions as people change their consumption patterns or chose to work less because taxation has changed the relative prices. The goal is to choose set of taxes to minimize total DWL subject to a constraint on the tax revenue the system raises. This maximization problem generates a relatively simple formula in which taxes reduce the compensated demand for each commodity equally. Under one common formulation of this result, if leisure is not taxed, we want to tax more highly goods that are complements for leisure, in effect trying to indirectly tax leisure. However, if implemented fully, a Ramsey tax would be truly complexity. Also, commodities under a Ramsey tax are not defined - they are any consumption good. If goods differ in any way, they are different commodities and would get a different tax rate. Thus, there would be too many different rates. Because the models do not have administrative costs, they describe tax systems of essentially unlimited complexity.

The second strand of tax literature, originating with James Mirrlees, focuses on the distributive basis for taxation (Mirrlees 1971). In Mirrlees's model, people vary by their ability to earn wage income but the government cannot directly observe ability; it can only observe total wage income. The goal is to maximize a social welfare function. Because marginal utility declines with income, social welfare can be improved through redistribution, so we do not want a uniform head tax. We cannot directly observe ability, however, so we also cannot have a differentiated head tax. Therefore, we tax wages as an indirect method of taxing ability. That is, unlike the Ramsey model which arbitrarily imposes a restriction in available taxes, the Mirrlees model imposes restrictions based on the information available to the government and an explicitly stated social goal. The problem with taxing wages rather than earning is that if the government taxes high earners at a high rate, they can reduce their effort and earn less, in effect pretending to be low-ability individuals. The optimal solution, which is complex, trades off the benefit of redistribution to low-ability individuals and the costs of higher-ability individuals reducing their labor effort. The Mirrlees model mainly considers only labor income taxes. The rate structure may be complex and individuals may not understand the structure. Further, "extended versions of the model add additional complexity" (Kaplow 2008: 135). One reason is that it may be desirable to tax more highly goods that are complementary to leisure to make reducing labor effort less attractive. Another reason is that taxpayers may have preferences related to their underlying ability. And taxpayer heterogeneity (i.e., holding income fixed) might optimally be taken into account. Thus, if someone gets less utility from a given income than others, the tax system might optimally differentiate among taxpayers with different characteristics. In summary, either the Ramsey approach or the Mirrlees approach is taken, the optimal tax system is likely complex. Therefore, knowledge of the tax law is essential.

Third, there are different types of taxes. A Pigouvian tax or subsidy is designed to cause people to internalize externalities. It is optimally set equal to the marginal harm or benefit from an activity. For example, a carbon tax would be set equal to the additional harm from climate change due to another unit of carbon in the atmosphere. Hence, we can think of Pigouvian taxes as substitutes for tort liability. Both are systems for causing individuals to consider external harms when they take actions. Other taxes are designed either to simply raise revenue for the purchase of public goods or to redistribute. In the Ramsey tax tradition, there is a fixed government budget that must be met.

In the Mirrlees tradition, taxes also redistribute. As noted, the effect of knowledge of the tax law may vary depending on the type of tax. Considerations about knowledge of tort laws likely apply to Pigouvian taxes but not to other taxes. Therefore, understanding the type of tax at issue will be important to understanding the effect of knowledge of the tax law. However, it is not always easy to determine whether a particular tax is a Pigouvian tax.

Finally, an aspect of the examples above is that they only considered the efficiency aspects of knowledge of the tax law, not the distributive effects. Policies that affect knowledge of the law might have distributive effects, so perhaps these should also be taken into account. However, we can always adjust tax rates to offset the distributive effects. For example, suppose that knowledge of the tax law allows high income taxpayers to reduce their marginal rate from $35 \%$ to $30 \%$ and we are considering a policy that would reduce knowledge of the tax law and thereby raise their rate to $35 \%$. To determine whether the policy is desirable, we want to compare it to alternative policies. 
For instance, instead of adopting the policy concerning knowledge of the law, we might simply increase marginal rates so that the effective rate goes up to $35 \%$. The two policies - the knowledge policy and the increase in rates have the same distributive effect but likely have different efficiency effects. We can compare them simply by examining their efficiency effects. Alternatively, we could compare not adopting the knowledge policy and adopting it plus lowering rates to $30 \%$. Again, the distributive effect would be the same and we need only examine the efficiency effects.

\section{Section 2: Applications and Extensions}

An alternative approach to understanding knowledge of the tax law is to ask whether the right amount will be supplied by the market. That is, do people have a socially optimal incentive to seek tax advice? Suppose that the tax is set optimally and consider an individual seeking advice on the tax law. Does the individual's private value of the advice equal the social value of the advice? An initial intuition might be that taxpayers have too low an incentive to seek advice. If tax advice reduces DWL, taxpayers may have too low an incentive to seek advice because they only consider the effect of advice on their own utility. Thus, reducing DWL might be like a positive externality from advice. However, the initial intuition may not be correct. DWL is the difference between the individual utility losses from taxation and the revenue raised. Individuals deciding to seek tax advice will fully consider the effects on their utility. The only possible externality from seeking advice, therefore, is the change in revenue.

In this setting, therefore, where taxpayer views about the content of the law are unbiased, taxpayers may equally end up paying more or paying fewer taxes once they learn the actual content of the law. For example, suppose there are two goods, food and automobiles and individuals purchase equal amount of each. The tax rate on food is $2 \%$ and the tax on automobiles is $12 \%$, for an average of 6\%. They may believe that the tax on food is higher than it is and the tax on automobiles lower, or vice versa. Hence, it is not clear if they learn the true rates whether they would pay less or more tax. If the perceived tax on food is higher than the true tax and the tax on automobiles lower, when individuals find out the true rate they will increase their food purchases and reduce their automobile purchases. Whether this reduces revenue depends on the demand elasticities for each of the items. If their perceptions are reversed, the results may be the reverse. Therefore, incentives to seek advice may be too low or too high.

Secondly, one of the most significant areas of tax regulation has been the regulation of tax advisors. However, tax advice is more expensive to give and its value lower. In a sense, the government has raised the cost of obtaining knowledge of the tax law and the question is whether this set of regulations is desirable. As we know, evaluating these regulations is complex and raises issues beyond merely whether knowledge of the tax law is desirable. Tax advice takes place in a complex institutional setting that involves law firms, clients, and the government. Principalagent problems abound in each of these settings and interact when tax advice is sought and given. Tax rules interact with other regulatory regimes, such as the accounting rules or securities laws. There are multiple purposes behind tax laws, and tax laws may often substitute for simple direct spending. And all of this takes place within the context of democratic law making with the attendant free speech concerns. Given these complexities, one might expect that the regulation of tax advice should increase its cost in cases where knowledge of the tax law is undesirable and reduce its cost where knowledge of the tax is desirable. Therefore, one way to see this set of regulations is as an attempt by the government to limit or make more expensive access to knowledge of the tax law where such knowledge is undesirable.

Finally, imagine a tax that is completely hidden where taxpayers are given no information about the tax until the last day of the year, at which point it is announced. To prevent the government from acting strategically, one could force the government to write the tax down on the first day of the year but only reveal it at the end of the year. This example, however, is an extreme version of more modest proposals aimed at manipulating knowledge or salience of the tax law. For example, Chetty and Saez (2009: 34)) conduct an experiment in which they teach low income taxpayers about the earned income tax credit, manipulating knowledge of the tax law by increasing it. They suggest that individuals confuse their average and marginal rates. Marginal rates decline in the relevant range, which means that individuals are assuming that marginal rates are higher than they actually are.

Increasing knowledge of the law, they suggest, can reduce DWL. Similarly, Liebman and Zeckhauser (2004) suggest that lack of knowledge can be a good thing if, when rates are increasing, people assumes that their marginal rate is equal to the average rate. They calculate that DWL from taxation is roughly half because of this lack of knowledge of marginal rates. The implication is that we should not make the marginal rate structure more transparent and might even benefit by making it less visible.

Thus, it is sufficiently difficult to know when knowledge of the tax law is desirable, that one should be cautious about attempting to manipulate salience. Doing so might very well increase rather than reduce the costs of taxation. Hence, one should consider the factors that might help he or she know when there is good idea or not. As a primary matter, one should only manipulate salience when there is likely that it will increase efficiency. To know when reducing salience increases efficiency one has to determine expectations about the tax in the absence of good knowledge, the quality of the tax and the type of tax. However, there is little consensus about which taxes is desirable, even the type of tax may not be easy to determine. 
For example, a tax on complements to leisure - suggested by the standard Ramsey formulation of the optimal revenue raising tax - can be seen as Pigouvian because its goal is to reduce the fiscal externalities caused by working less. This is not to say that taxpayer never know when knowledge of the tax is undesirable. For example, Liebman and Zeckhauser consider graduated labor income taxes and argue that lack of knowledge about marginal rates reduce the DWL. They claim that individuals assume the marginal rate is the average rate, so expectations are unbiased and there are no income effects. If this is true and marginal rats are increasing, it may not matter that the rate schedule is not likely to be optimal and for any given rate, the labor leisure distortion is less.

\section{References}

Allingham, Michael G. and Agnar Sandmo. 1972. "Income tax evasion: a theoretical analysis." Journalof Public Economics 1: 323-338.

Bartolome, Charles A. 1995. "Which tax rate do people use: Average or marginal?"Journal ofPublic Economics 56: 79-96.

Blumkin, Tomer, Bradley J. Ruffle and Yosef Ganun. 2008. "Are Income and Consumption Taxes EverReally Equivalent? Evidence from a Real-Effort Experiment with Real Goods."CESifoWorking Paper Series, No. 2194.

Boylan, Scott J. and Peter J. Frischmann. 2006. "Experimental Evidence on the Role of TaxComplexity in Investment Decisions." Journal of the American Taxation Association 28:69-88.

Buchanan, James M. and Richard A. Musgrave. 1999. "Public Finance and Public Choice: Two Contrasting Visions of The State." Cambridge, Massachusetts: MIT Press.

Chetty, Raj, Adam Looney and Kory Kroft. 2009. "Salience and Taxation: Theory and Evidence." American Economic Review 99: 1145-1177.

Chetty, Raj and Emmanuel Saez. 2009. "Teaching the Tax Code: Earning Responses to an Experiment with EITC Recipients."NBER Working Paper, No. 14836.

Congdon, William, Jeffrey R. Kling and Sendhil Mullainathan. 2009. "Behavior Economics and Tax Policy." National Tax Journal 62: 375-386.

Cullis, John and Adam Lewis. 1985. "Some hypotheses and evidence on tax knowledge andPreferences."Journal of Economic Psychology 6: 271-287.

Diamond, Peter A. and James A. Mirrlees. 1971. "Optimal Taxation and Public Production 1: Production Efficiency." American Economic Review 61: 8-27.

Enrick, Norbert. 1964. "A Further Study of Income Tax Consciousness.” National Tax Journal

17: 319-321.

Feld, Lars P. and Jean-Robert Tyran. 2002. "Tax Evasion and Voting: An Experimental Analysis.” KYKLOS 55: 197-222.

Fortin, Bernard, Guy Lacroix and Marie-Claire Villeval. 2007. "Tax evasion and social interactions." Journal of Public Economics 91: 2089-2112.

Fochmann, Martin, Dirk Kiesewetter and Abdolkarim Sadrieh. 2010. "Investment Behavior and the BiasedPerception of Limited Loss Deduction in Income Taxation."FEMM Working Paper, No. 04.

Fujii, Edwin T. and Clifford B. Hawley. 1988. "On the Accuracy of Tax Perceptions." Review of

Economics \& Statistics 70: 344-347.

Gensemer, Bruce L., Jane A. Lean and William B. Neenan. 1965. "Awareness of Marginal Income TaxRates Among High-Income Taxpayers."National Tax Journal 18: 258-267.

Gruber, Jonathan. 2009. Public Finance and Public Policy. Worth Publishers.

Guth, Werner and Rupert Sausgruber. 2008. "Voting between tax regimes to fund a public good." Economics of Governance 9: 287-303.

Guth, Werner, Sabine Straub and Matthias Sutter. 2005. "Tax Evasion and State Productivity - AnExperimental Study." Metroeconomica 56: 85-100.

Haig, Robert M. 1921. The Concept of Income - Economic and Legal Aspects. New York: Columbia University Press.

Harbaugh, William T., Ulrich Mayr and Daniel R. Burghart. 2007. "Neural Responses to Taxation andVoluntary Giving Reveal Motives for Charitable Donations.” Science 316: 1622-1625.

Kaplow, Louis. 2008. The Theory of Taxation and Public Economics. Princeton University Press.

Kolm, Serge-Christophe. 1973. “A note on optimum tax evasion.” Journal of Public Economics 2: 265-270.

Konig, Heinz, FranCois Laisney, Michael Lechner and Winfried Pohlmeier. 1995. "Tax illusion and labor supplyof married women. Evidence from German data." KYKLOS 48: 347-368.

Lewis, Alan. 1978. "Perceptions of Tax Rates."British Tax Review 6: 358-366.

Lewis, Alan. 1979. "An empirical assessment of tax mentality."Public Finance 34: 245.-257.

Liebman, Jeffrey B. and Richard J. Zechhauser. 2004. "Schmeduling." Unpublished manuscript.

Lindbeck, Assar. 1982. "Tax effects versus budget effects on labor supply."Economic Inquiry 
20: 473-489.

Musgrave, Richard. 1967. "In Defense of an Income Concept." Harvard Law Review 81: 44.

Peek, Joe and James A. Wilcox. 1984. "The Degree of Fiscal Illusion in Interest Rates: Some Direct Estimates."American Economic Review 74: 1061-1066.

Rosen, Harvey. 1976a. "Tax Illusion and the Labor Supply of Married Women."Review of

Economics \& Statistics 58: 167-172.

Rosen, Harvey. 1976b. "Taxes in a labor supply model with joint wage-hours determination."

Econometrica 44: 485-507.

Ruffle, Bradley. 2005. "Tax and subsidy incidence equivalence theories: experimental evidencefrom competitive markets. The Experimental Approaches to Public Economics."Journalof Public Economics 89: 15191542.

Rupert, Timothy J. and Carol M. Fischer. 1995. "An Empirical Investigation of Taxpayer Awareness of Marginal Tax Rates."Journal of the American Taxation Association 17: 36-59.

Rupert, Timothy J., Louise E. Single and Arnold M. Wright. 2003. "The Impact of Floors and Phase-Outs on Taxpayers' Decisions and Understanding of Marginal Tax Rates."Journal of the

American Taxation Association 25: 72-86.

Rupert, Timothy J. and Arnold M. Wright. 1998. "The Use of Marginal Tax Rates in Decision Making:The Impact of Tax Rate Visibility."Journal of the American Taxation Association 20: 83-99.

Sausgruber, Rupert and Jean-Robert Tyran. 2005. "Testing the Mill hypothesis of fiscal illusion." PublicChoice 122: 39-68.

Schenk, Deborah. 2010. "Exploiting the Salience Bias in Designing Taxes." NYU Law and Economics Research Paper No. 10-37.

Sillamaa, Mary-Anne. 1999a. "How work effort responds to wage taxation: A non-linear versus a linear tax experiment."Journal of Economic Behavior \& Organization 39: 219-233.

Sillamaa, Mary-Anne. 1999b. "How work effort responds to wage taxation: An experimental testof a zero top marginal tax rate."Journal of Public Economics 73: 125-134.

Sillamaa, Mary-Anne. 1999c. "Taxpayer behavior in response to taxation: comment and newexperimental evidence."Journal of Accounting and Public Policy 18: 165-177.

Simons, Henry C. 1938. Personal Income Taxation: The Definition of Income as a Problem of Fiscal Policy. Chicago: University of Chicago Press.

Spicer, Michael W. and Lee A. Becker. 1980. "Fiscal Inequity and Tax Evasion: An Experimental Approach.'National Tax Journal 33: 171-175.

Sutter, Matthias and Hannelore Weck-Hannemann. 2003. "Taxation and the Veil of Ignorance - A RealEffort Experiment on the Laffer Curve."Public Choice 115: 217-240.

Swenson, Charles. 1988. "Taxpayer behavior in response to taxation: An experimentalAnalysis."Journal of Accounting and Public Policy 7: 1-28.

Vogel, Joachim. 1974. "Taxation and Public Opinion in Sweden: an Interpretation of Recent Survey Data."National Tax Journal 27: 499-513. 